\title{
Direito Indígena e o Paradigma Instituído pela Constituição de 1988: direito à alteridade
}

Recebido: 02-01-2018

Aprovado: 09-05-2018

\author{
Rafael Alem Mello Ferreira ${ }^{1}$ \\ Fabiana Bittencourt ${ }^{2}$ \\ Alisson Jordão Rêgo ${ }^{3}$
}

\section{Introdução}

A Constituição Federal de 1988 marca uma nova visão a respeito dos direitos dos índios, à luz das concepções antropológica e jurídicas, que, ao contrário das constituições anteriores que tinham a intenção de integrar o índio à comunidade nacional, aniquilando a cultura indígena e desrespeitando suas diferenças, busca respeitar a sua especificidade étnico-cultural, garantindo-lhe o direito de ser e de permanecer índio. Assim, a ordem constitucional instituída pela referida Constituição tem como mote a mudança de paradigma, abolindo a tentativa de integração e adotando a concepção de interação.

A partir dessa ótica, o objetivo do presente trabalho será estudar a nova ordem instaurada pela Constituição de 1988 no tocante aos direitos dos povos indígenas em relação aos direitos que eram a estes atribuídos anteriormente, à maneira como este eram tratados pelos ordenamentos jurídicos anteriores e as alterações promovidas pelo advento da nova ordem constitucional promulgada em 1988.

Destarte, o primeiro item do presente trabalho refere-se à análise do contexto vivenciado pelos povos indígenas durante o regime militar, no intuito de demostrar o tratamento dispendido aos povos indígenas pelo ordenamento jurídico brasileiro principalmente no momento anterior à promulgação da Constituição de 1988.

\footnotetext{
${ }^{1}$ Doutor em Direito pela Universidade Estácio de Sá. Professor da Faculdade de Direito do Sul de Minas (FDSM) e Coordenador e professor do Curso de Direito da PUC-MG.

${ }^{2}$ Mestra pela Faculdade de Direito do Sul de Minas - Área de concentração: Constitucionalismo e Democracia. Bacharela em Direito pela Faculdade de Direito do Sul de Minas. Participante dos grupos de pesquisa "Reflexões Críticas sobre Direitos Fundamentais e Garantias Constitucionais" e "Ultima Ratio";. Atualmente é professora substituta da disciplina de Instituições de Direito Penal I e II e Parte Especial do Direito Penal I pela Faculdade de Direito do Sul de Minas. Contato: fafabittencourt@hotmail.com

${ }^{3}$ Graduando em Direito na Faculdade de Direito do Sul de Minas e bolsista FAPEMIG. Tem suas pesquisas concentradas nas áreas de direito constitucional, direitos humanos e ciência política.
} 
Em seguida, o segundo item abordado neste trabalho tem por objetivo o estudo da criação do Estatuto do índio, suas influências, seu momento de produção, buscando demonstrar o contexto de sua formulação e a regulamentação decorrente das concepções à época predominantes.

Por fim, o último item tem por objeto de estudo a análise da Constituição Federal como construção de um novo paradigma ao direito indígena, abandonando o ideário de integração do índio e adotando a interação como modelo a ser seguido, demonstrando os impactos dessa nova forma de compreender a relação com os povos indígenas na intepretação das legislações protetoras já existentes.

\section{Os Povos Indígenas e a Ditadura Militar}

Durante a ditadura militar ocorrida entre os anos de 1964 a 1985, o Brasil viveu momentos de grande retrocesso em relação aos direitos individuais, por um lado e, de outro, o país viveu momentos de grande expansão devido ao milagre econômico e investimento de capital estrangeiro. Portanto, nessa época de antagonismos, houve várias construções de hidrelétricas e rodovias, levando um conflito de interesses entre Estado e indígena, com a restrição de direitos desses povos.

O conflito de interesses entre indígenas e grandes latifundiários, principalmente da região norte do país, por disputa de terras foi algo recorrente. Percebe-se, em tal período, uma omissão por parte do estado brasileiro, que se quedou inerte em relação aos conflitos de terras, ou, quando, atuava, defendia os interesses dos grandes proprietários em detrimento das minorias indígenas. Houve também violações diretas por parte do estado brasileiro, como mostra o relatório da Comissão Nacional da Verdade (2014):

\footnotetext{
Omissão e violência direta do Estado sempre conviveram na política indigenista, mas seus pesos respectivos sofreram variações. Poder-se-ia assim distinguir dois períodos entre 1946 e 1988, o primeiro em que a União estabeleceu condições propícias ao esbulho de terras indígenas e se caracterizou majoritariamente (mas não exclusivamente) pela omissão, acobertando o poder local, interesses privados e deixando de fiscalizar a corrupção em seus quadros; no segundo período, o protagonismo da União nas graves violações de direitos dos índios fica patente, sem que omissões letais, particularmente na área de saúde e no controle da corrupção, deixem de existir’’4.
}

No contexto acima descrito, grande obra realizada durante o regime militar foi a construção da Transamazônica, que tinha como objetivo integrar o Norte do país. Tal rodovia passaria por sete estados brasileiros, promovendo fácil acesso e circulação de pessoas, bens e serviços, visando ao desenvolvimento político e econômico de tal região do país. Entretanto, em que pese a grande repercussão que a construção promoveria, sua execução foi abandonada

\footnotetext{
${ }^{4}$ Disponível em: http://www.cnv.gov.br/ Texto 5, p. 204.
} 
no meio do percurso, tornando-se umas das principais obras inacabadas do país. Todavia, em que pese seu status de inacabada, para a construção de tal estrada, na época, foi necessário remover vários povos indígenas de suas terras, além de afetar de maneira trágica 29 etnias, através de doenças e conflitos, conforme destaca o relatório da CNV. Ademais, outras rodovias foram construídas durante tal regime, trazendo também grandes impactos à população indígena. Como relata o relatório da CNV (2014):

\begin{abstract}
Vários documentos e relatos colhidos durante as investigações recentes da Comissão Nacional da Verdade apontam que cerca de 8 mil indígenas foram mortos, em conflitos, crises de abastecimento ou epidemias trazidas pelos trabalhadores, em consequência da construção de quatro rodovias: a Transamazônica; a BR-174, que liga Manaus a Boa Vista; a BR-210, conhecida com Perimetral Norte; e a BR 163, que liga Cuiabá a Santarém. Essas estradas faziam parte do Plano de Integração Nacional (PIN), instituído em 1970, pelo presidente Emílio Garrastazu Médici. O PIN previa que 100 quilômetros em cada lado das estradas a serem construídas deveriam ser destinados à colonização. A intenção do governo era assentar cerca de 500 mil pessoas em agrovilas que seriam fundadas nesses locais $^{5}$
\end{abstract}

Tais obras tinham como objetivo realizar a integração do índio com o homem branco. Tal integração seria realizada através das grandes construções, transformando os povos indígenas afetados em trabalhadores que, aos poucos, iam se integrando à comunidade e passando a ser “civilizados”. Uma declaração dada em 1972, pelo superintendente da Funai na época, o general Ismarth de Araújo, explicou ao jornal O Estado de S. Paulo que "índio integrado é aquele que se converte em mão de obra" e que essa integração se daria de forma "lenta e harmoniosa".

Com o a decretação do Ato Institucional n. ${ }^{\mathrm{o}} 5^{\mathrm{a}}-\mathrm{AI}-5^{7}$ - pelo governo militar, houve uma maior perseguição política por parte do governo contra seus opositores, sendo, por reflexo, também afetados os povos indígenas por tal medida, vez que qualquer um que resistisse às políticas de integração da $\mathrm{FUNAI}^{8}$ seria perseguido.

\footnotetext{
${ }^{5}$ Disponível em: http://memoriasdaditadura.org.br/indigenas/ acesso em: 02/03/2017

${ }^{6}$ Disponível em: http://memoriasdaditadura.org.br/indigenas/ acesso em: 25/10/2016

${ }^{7}$ O Ato Institucional $\mathrm{n}^{\circ}$ 5, AI-5, baixado em 13 de dezembro de 1968, durante o governo do general Costa e Silva, foi a expressão mais acabada da ditadura militar brasileira (1964-1985). Vigorou até dezembro de 1978 e produziu um elenco de ações arbitrárias de efeitos duradouros. Definiu o momento mais duro do regime, dando poder de exceção aos governantes para punir arbitrariamente os que fossem inimigos do regime ou como tal considerados. Disponível em: http://cpdoc.fgv.br/producao/dossies/FatosImagens/AI5 acesso em: 25/10/2016

${ }^{8}$ A Fundação Nacional do Índio - FUNAI é o órgão indigenista oficial do Estado brasileiro. Criada por meio da Lei $\mathrm{n}^{\circ}$ 5.371, de 5 de dezembro de 1967, vinculada ao Ministério da Justiça, é a coordenadora e principal executora da política indigenista do Governo Federal. Sua missão institucional é proteger e promover os direitos dos povos indígenas no Brasil. Cabe à FUNAI promover estudos de identificação e delimitação, demarcação, regularização fundiária e registro das terras tradicionalmente ocupadas pelos povos indígenas, além de monitorar e fiscalizar as terras indígenas. A FUNAI também coordena e implementa as políticas de proteção aos povos isolados e recém-contatados. Disponível em: http://www.funai.gov.br/index.php/quem-somos acesso em: $25 / 10 / 2016$
} 
Durante essa época, prisões específicas para os indígenas se tornaram comuns. Tais instituições recebiam o nome de reformatório, mas pouco se sabe sobre o que realmente acontecia lá e os seus propósitos. A organização Memórias da Ditadura relata que:

Em 1969, por exemplo, começou a funcionar no município de Resplendor (MG) o Reformatório Agrícola Indígena Krenak, um "centro de recuperação" de índios mantido pela ditadura militar. Indígenas de todas as regiões do Brasil foram jogados em suas celas, acusados por "crimes", como vadiagem, consumo de álcool e pederastia (homossexualidade masculina). No Reformatório do Krenak, os militares também forçaram a criação de milícias indígenas, as Guardas Rurais Indígenas (GRINs), treinadas para aplicar técnicas de tortura criadas pelo homem branco. Esse experimento sinistro do regime militar até hoje é cercado de mistérios ${ }^{9}$

Um depoimento que a CNV destaca é o de Oredes Krenak, que conta o que passou em um desses reformatórios, mostrando que a violência era recorrente em tais lugares:

\begin{abstract}
Bater era normal para eles. Se o índio tentava se justificar por alguma acusação, batiam com cassetete grande, depois jogavam na prisão. Não podiam nem perguntar por que estavam sendo punidos. Também batiam de chicote. Algemavam o preso dentro da cadeia e ele não podia falar, argumentar. Ameaçavam com arma. Os mais antigos contam que quando matavam um índio, jogavam no rio Doce e diziam para os parentes que tinha ido viajar. Quando estavam muito debilitados, jogavam no hospital. A gente não sabia se estavam mesmo no hospital ou se foram massacrados ou morreram de fome, sede. A gente não via morrer aqui, era quando estavam no hospital. Até a década de 1980 nosso povo sofreu bastante com os militares ${ }^{10}$.
\end{abstract}

Vale destacar o Relatório Figueiredo, escrito pelo promotor que percorreu o Brasil durante os anos de 1968 e 1969, apurando as violações de direitos ocorridas contra os povos indígenas. Há relatos de campos de concentração onde os índios eram presos e torturados. Tal documentos foi redescoberto em 2013, após supostamente ser eliminado em um incêndio no Ministério da Agricultura. Ele foi encontrado no Museu do Índio, no Rio de Janeiro, com mais de 7 mil páginas preservadas e contendo 29 dos 30 tomos originais.

Os resultados da tentativa de integração de povos indígenas durante o regime foi desastroso, causando mortes e sofrimento, através a ação e omissão e do Estado Brasileiro, como conclui o relatório da $\mathrm{CNV}$ :

Como resultados dessas políticas de Estado, foi possível estimar ao menos 8.350 indígenas mortos no período de investigação da CNV, em decorrência da ação direta de agentes governamentais ou da sua omissão. Essa cifra inclui apenas aqueles casos aqui estudados em relação aos quais foi possível desenhar uma estimativa.

O número real de indígenas mortos no período deve ser exponencialmente maior, uma vez que apenas uma parcela muito restrita dos povos indígenas afetados foi analisada e que há casos em que a quantidade de mortos é alta o bastante para desencorajar estimativas. ${ }^{11}$

A violência contra os povos indígenas está presente desde o início da colonização, e, apesar de ter diminuído ao longo dos anos com a criação de fundações específicas para

\footnotetext{
${ }^{9}$ Disponível em: http://memoriasdaditadura.org.br/indigenas/ acesso em: 25/10/2016

${ }^{10}$ Arquivo CNV, 00092.003063/2014-40, Depoimento de Oredes Krenak.

${ }^{11}$ Disponível em: http://www.cnv.gov.br/ Texto 5, p. 205.
} 
amparo e proteção dos povos indígenas, ainda está presente em nossa sociedade. Prova disso foi esse recente histórico na ditadura militar que mostra ser necessário um estudo mais profundo a respeito desse povo que sempre viveu em nossas terras e sofreu como o modo de civilização que é imposta a eles.

\section{A Criação do Estatuto do Índio}

A tentativa de integrar o indígena ao modo de viver predominante do povo colonizador causa inúmeras controversas. Isso se deve à dificuldade de compreender uma cultura totalmente diferente e tentar impor um modo de viver para tais indivíduos. Durante muito tempo o Estado Brasileiro foi pensando em modos que poderiam integrar de vez os povos indígenas à sua cultura, não os entendendo como sujeitos de cultura própria e independente.

O estatuto do índio surgiu durante o período da ditadura militar. Foi promulgado através da Lei $\mathrm{n}^{\circ} 6001$ de 1973 e tinha como principal objetivo integrar o indígena com o "homem civilizado", o que se percebe logo em seu primeiro artigo:

Art. $1^{\circ}$ - "Esta Lei regula a situação jurídica dos índios ou silvícolas e das comunidades indígenas, com o propósito de preservar sua cultura e integrá-los, progressiva e harmoniosamente, à comunhão nacional".

O Estatuto do Índio surgiu no período autoritário, sendo instituído com a intenção de responder à comunidade internacional sobre inúmeras denúncias de extermínio de populações indígenas em território nacional ${ }^{12}$. Entretanto, em razão do período em que foi criando, ainda apresenta como fundamento a futura integração, ou seja, visa a garantir temporariamente alguns direitos, eliminando aos poucos o elemento índio, já que com o passar do tempo, este iria perder sua cultura original, deixando de ser índio e se incorporando à comunidade nacional (isolados, em vias de integração e integrados - o Código Civil de 1916, vigente à época, previa que os índios eram relativamente incapazes - art. $6^{\circ}$, IV).

O Estatuto do Índio, nesse sentido, corrobora a visão adotada à época pelo Código Civil de 1916, que previa ser o índio relativamente incapaz, ou seja, não sendo capaz de exercer por si

12 COLAÇO, Thais Luzia. Os "novos" direitos indígenas. In: WOLKMER, Antonio Carlos; LEITE, José Rubens Morato (orgs.). Os "novos" direitos no Brasil: naturezas e perspectivas: uma visão básica das novas conflituosidades jurídicas. São Paulo: Saraiva, 2003. p.87. 
alguns de seus direitos, dependendo, portanto de representante para expressão de sua vontade e para a prática dos atos da vida civil.

Tal representação deveria ocorrer através de um ente estatal que, de 1910 a 1967 era a SPI (Serviço de Proteção ao Índio) e atualmente a FUNAI (Fundação Nacional do Índio). O auxílio de tais entes seria necessário até ocorrer a integração do índio à sociedade, ou seja, eles previam que com o passar do tempo, o modo de viver do "homem civilizado" iria alcançar o indígena que se adaptaria a isso. Logo, o objetivo do paradigma da integração do índio era que, em determinado momento, a figura indígena deixaria de existir, posto que estariam todos os índios integrados ao ordenamento jurídico e, portanto, civilizados.

$\mathrm{Na}$ época da criação do Estatuto do Índio, muito se discutia a respeito de como essa integração do índio deveria ser feita. Algumas pessoas defendiam a ideia que o índio precisava trabalhar e com isso iria se integrar a realidade do homem branco. Assim, o índio deveria servir de força de trabalho e, consequentemente, passaria a integrar a comunidade e se tornaria civilizado, deixando de ser índio.

Por ter sido promulgado durante o regime militar a ideia de integração era muito forte e tal fato ocorreria através da exploração da mão de obra indígena como destaca o Relatório da Comissão Nacional da Verdade ${ }^{13}$ :

\begin{abstract}
A ideia de integração se apoia em abertura de estradas, particularmente a Transamazônica e a BR 163, de Cuiabá a Santarém, além das BR 174, 210 e 374. A meta era assentar umas 100 mil famílias ao longo das estradas, em mais de 2 milhões de quilômetros quadrados de terras expropriadas. Na época, o ministro do Interior era o militar e político José Costa Cavalcanti, um dos signatários do AI5, que ficaria no cargo de 1969 até 1974, apoiado por Costa e Silva (a quem ajudara a ascender a presidente) e por Médici. Costa Cavalcanti ele próprio declara que a Transamazônica cortaria terras de 29 etnias indígenas, sendo 11 grupos isolados e nove de contato intermitente - acarretando em remoções forçadas. Para a consecução de tal programa, a Funai, então dirigida pelo general Bandeira de Mello, firmou um convênio com a Superintendência de Desenvolvimento da Amazônia (Sudam) para a "pacificação de 30 grupos indígenas arredios" e se tornou a executora de uma política de contato, atração e remoção de índios de seus territórios em benefício das estradas e da colonização pretendida.
\end{abstract}

A partir do desenvolvimento dessas estradas, o povo indígena teria mais oportunidades de contato com o homem branco, consequentemente se adaptaria melhor a sua cultura. A ideia principal dessas grandes estradas era proporcionar maior ocupação habitacional na região amazônica, visando à exploração de suas riquezas naturais. Contudo, causou grandes impactos nos povos indígenas, como doenças e mortes, além da invasão de suas terras.

${ }^{13}$ Disponível em: http://www.cnv.gov.br/ Texto 5, p. 209 
O grande objetivo do Estatuto do Índio era garantir direitos para o povo indígena demarcação de suas terras, garantindo assistência ou até mesmo ajudando na regulamentação fundiária. O Estatuto representou um avanço em relação ao modo em que o indígena era tratado antes, afinal começava-se a estabelecer métodos para as demarcações de suas terras, uma luta muito antiga.

Entretanto, o Estatuto apresenta falhas sobretudo ao reconhecimento de sua cultura e demarcação de terras que apesar da previsão ainda não foi totalmente regulamentada; ao contrário, a demarcação de terras acabava por ser efetuada de maneira que privilegiava os grandes proprietários de terras e os interesses econômicos, sendo destinadas aos índios parcelas de terras que não correspondiam ao seu ambiente de origem. A própria FUNAI reconhece tais problemas ao destacar:

\footnotetext{
Entretanto, a nova política indigenista continuou ambígua no que se refere ao reconhecimento da especificidade cultural dos índios, pois propunha se a proteger as diferentes culturas indígenas ao mesmo tempo em que objetivava sua integração na sociedade brasileira. Mesmo com os avanços alcançados na abordagem da questão indígena, a função de tutela continuou sendo exercida pelo Estado reforçando a relação paternalista e intervencionista deste para com as sociedades indígenas, mantendo-as submissas e dependentes. ${ }^{14}$
}

Já se passaram mais de 40 anos desde a promulgação desse estatuto, no entanto, há vários problemas ainda a serem solucionados a respeito do povo indígena. Dentre eles, vale destacar a demarcação de terras que ainda é um grande problema entre latifundiários e índios. Outro problema ainda existente é a respeito de sua preservação cultural e integração a sociedade.

A Constituição da República de 1988, inovou ao trazer mais direitos e garantias para o povo indígena. Por isso já há no Congresso desde os anos 90 projetos de novos estatutos indígenas, trazendo mais direitos e regulando mais situações. O debate acerca desses povos deve ser trabalhado e discutido vez que devem ter seus direitos constitucionais efetivados.

\section{A Promulgação da Constituição de 1988 e os Povos Indígenas}

Após o fim da ditadura militar, uma nova constituição foi promulgada alguns anos depois para garantir novamente um Regime Democrático no Brasil. Com esse novo documento, uma série de direitos fundamentais foram inseridos a todos os brasileiros, muito deles inéditos tornando a nova carta Magna conhecida como "Cidadã".

\footnotetext{
14 Disponível em: http://www.funai.gov.br/index.php/nossas-acoes/politica-indigenista?start=2 acesso em: $02 / 03 / 2017$
} 
Os indígenas não ficaram de fora dessas novidades e começaram a ser enxergados de uma maneira diferente pelo direito. Tais garantias trazidas pela nova carta constitucional jamais tinham sido vistas nas outras constituições e legislações, instituindo um novo marco no que diz respeito ao direito indígena, conforme destaca José Theodoro Mascarenhas Menk ${ }^{15}$ :

Efetivamente com a nova ordem jurídica, implantada pela Carta constitucional de 1988, abriuse um novo capítulo na história brasileira, em relação ao índio [...]. Ao índio agora se reconhece o direito à diferença a uma individualidade própria. Sem que tenha havido qualquer retorno a fase colonial, concedeu-lhes direitos inimagináveis [...] Não se pode negar que o tratamento jurídico dispensado às populações indígenas foi revolucionado pela Carta de 1988.

Um dos primeiros pontos que merecem ser destacados na Constituição de 1988, sobre os indígenas é o fato de não ter mais a ideologia de integração do índio, podendo ele permanecer com sua cultura. Portanto, se reconhece ao indígena o direito a ter uma organização social, costumes e outros hábitos de seu povo como uma garantia constitucional devendo ser respeitada. Isso é notado logo no caput do artigo 231 da Constituição Federal.

Art. 231. São reconhecidos aos índios sua organização social, costumes, línguas, crenças e tradições, e os direitos originários sobre as terras que tradicionalmente ocupam, competindo à União demarcá-las, proteger e fazer respeitar todos os seus bens.

O Estado deve, portanto, respeitar e garantir tal proteção a esse povo, criando meios que protejam sua cultura e seus costumes. $\mathrm{O}$ índio é diferente e isso foi uma grande inovação trazida pela constituição, respeitando essa diferença. A ideia de índio integrado não deve ser mais utilizada, por isso a Constituição brasileira se destaca ao respeitar a cultura desse povo originário, instituindo o paradigma da alteridade, representado pelo direito de ser e de permanecer índio. Nesse sentido destaca Carlos Frederico Marés Souza ${ }^{16}$ :

\begin{abstract}
A Constituição de 1988 rompe o paradigma da assimilação, inclusão ou provisoriedade da condição indígena [...]. A partir de 1988 fica estabelecida uma nova relação do Estado Nacional com os povos indígenas habitantes de seu território. Está claro que a generosidade de integrar indivíduos que assim desejar na vida nacional ficou mantida em toda sua plenitude, mas integrando-se ou não, o Estado Nacional reconhece o direito de continuar a ser índio, coletivamente entendido, de continuar a ser grupo diferenciado, sociedade extremamente organizada $^{17}$.
\end{abstract}

Outro aspecto que merece quanto à Constituição de 1988 em relação ao indígena é quanto a sua capacidade e representação. Afinal, o índio, antes da Constituição, era visto como relativamente incapaz, e, portanto precisava de um representante legal para pleitear seus

${ }^{15}$ MENCK, José Theodoro Mascarenhas O problema indígena perante o ordenamento jurídico das Américas. In: Revista da OAB, ano XXII, v. XX, n.55, 1991, p. 132.

${ }^{16}$ SOUZA FILHO, Carlos Federico Marés de, $O$ direito de ser povo, In: Ordem Jurídica étnico-racial, p. 468. Apud OLIVEIRA, Paulo Henrique de, Direito Indígena à saúde: Proteção Constitucional e Internacional . Dissertação (Mestrado em Direito do Estado) - Pontifícia Universidade Católica de São Paulo. São Paulo, p.104. 2009

${ }^{17}$ OLIVEIRA, Paulo Henrique de, Direito Indígena à saúde: Proteção Constitucional e Internacional . Dissertação (Mestrado em Direito do Estado) - Pontifícia Universidade Católica de São Paulo. São Paulo, p.109. 2009 
direitos, nesses casos a FUNAI que exercia esse papel de representação da vontade dos indígenas. A Carta Magna de 1988, todavia, traz o Estado como responsável de proteger o indígena e em seu artigo 232 atribui a capacidade processual para esse povo, ao dizer que:

Art. 232. Os índios, suas comunidades e organizações são partes legítimas para ingressar em juízo em defesa de seus direitos e interesses, intervindo o Ministério Público em todos os atos do processo.

O artigo marca uma inovação no sentido que o índio agora não é mais incapaz para propor uma ação nem individualmente ou representando sua comunidade. O Ministério Público agora irá intervir em todos os atos do processo como procurador dos interesses desse sujeito. Nesse sentido, Pinto Ferreira destaca que a Constituição de 1988, sobre a capacidade processual indígena,

deu nova rota à matéria [...] os índios não são mais incapazes [...] assim pessoalmente têm denominada legitimidade as causam. Destarte a pessoa do índio está acima da União e da Funai para mover uma ação judicial, podendo contratar advogado ou utilizar-se da assistência judiciária $^{18}$.

Devido a esse novo tratamento dado ao indígena quanto sua capacidade processual, o Código Civil de 2002 retira o índio da categoria dos relativamente incapazes, dizendo que os mesmos serão regulados por uma Lei especial.

Tais inovações trazidas pela Constituição contradizem algumas ideias que o Estatuto do Índio determina, principalmente no que diz respeito à integração e à capacidade, reconhecendo também seus direitos às terras que ocupam, como destaca Roberto Lemos Santos Filho ${ }^{19}$ :

Contrariando diversos aspectos do Estatuto do Índio, a Constituição garantiu o multiculturalismo, o respeito às tradições, o reconhecimento dos direitos originários indígenas, a igualdade, o direito à diferença e às terras tradicionalmente ocupadas, dentre diversos outros.

A luta indígena por seus direitos é antiga e a possibilidade de defender tais direitos foi uma grande inovação trazida pela Constituição de 1988, conforme afirma Dalmo de Abreu Dallari $^{20}$ :

A possibilidade de defender seus interesses como direitos constitucionalmente assegurados representa significativa evolução na luta dos índios brasileiros por sua sobrevivência física e pela preservação de sua cultura tradicional.

${ }^{19}$ SANTOS, Roberto Lemos Filho, Índios, convenção 169 da OIT e meio ambiente. In: Revista do CEJ. Brasília, n.22, jul./set. 2003, p.18.

${ }^{20}$ DALLARI, Dalmo de Abreu.Argumento antropológico e linguagem jurídica. In: SILVA, Orlando Sampaio; Luiz, Lídia; HELM, Cecília M.V. (Orgs.). A perícia antropológica em processos judiciais. Florianópolis: UFSC, 1994, p. 109. 
A Constituição Federal de 1988 marca uma nova visão dos direitos dos índios, à luz das concepções antropológica e jurídicas, que, ao contrário das constituições anteriores que tinham a intenção de integrar o índio à comunidade nacional, aniquilando a cultura indígena e desrespeitando suas diferenças, busca respeitar a sua especificidade étnico-cultural, garantindo-lhe o direito de ser e de permanecer índio, provocando uma mudança de paradigma: de integração para interação $^{21}$.

O conceito de índio estabelecido pelo Estatuto do Índio, que foi recepcionado pela Constituição de 1988, com adequação de seus fundamentos e de suas interpretações considera índio:

Art. $3^{\circ}$, I: "todo indivíduo de origem e ascendência pré-colombiana que se identifica e é identificado como pertencente a um grupo étnico cujas características culturais o distinguem da sociedade nacional".

Entretanto, o conceito atual de índio é definido pela Convenção 169 da OIT, promulgada pelo Decreto $\mathrm{n}^{\circ}$ 5.051, de 19 de abril de 2004 que considera como povos tribais aqueles cujas condições sociais, culturais e econômicas os distingam de outros segmentos da comunidade nacional e cuja situação seja regida, total ou parcialmente, por seus próprios costumes ou tradições ou por uma legislação ou regulações especiais e como indígenas os que pelo fato de descenderem de populações que viviam no país ou região geográfica na qual o país estava inserido no momento da sua conquista ou colonização ou do estabelecimento de suas fronteiras atuais e que, independente de sua condição jurídica, mantêm algumas de suas próprias instituições sociais, econômicas, culturais e políticas ou todas elas.

Nessa perspectiva garantista, são direitos assegurados constitucionalmente aos índios (art. 231 e $232, \mathrm{CF} / 88)$ :

a) Direitos culturais: costumes, línguas, crenças e tradições;

b) Direito à auto-organização: reconhecida sua organização social;

c) Direitos territoriais - direito originário sobre a terra e posse permanente, inalienável, indisponível e imprescritível, com usufruto exclusivo das riquezas, sendo dever da União demarcá-las e protegê-las;

d) Direito à alteridade (direito de ser diferente) $)^{22}$ - direito de ser índio e de manter-se como índio;

${ }^{21}$ MAZUR, Bianca de Freitas. Os povos indígenas e seus direitos: a consagração com a Constituição de 1988. MINHOTO, Antonio (org.). Constituição, minorias e inclusão social. São Paulo: Rideel, 2009. p. 188.

${ }^{22}$ Idem, p. 186. 
e) Direito de permanência das terras, sendo vedada a remoção dos grupos indígenas de suas terras, salvo, "ad referendum" do Congresso Nacional, em caso de catástrofe ou epidemia que ponha em risco sua população, ou no interesse da soberania do País, após deliberação do Congresso Nacional, garantido, em qualquer hipótese, o retorno imediato logo que cesse o risco.

f) Direito de petição:

Art. 232. Os índios, suas comunidades e organizações são partes legítimas para ingressar em juízo em defesa de seus direitos e interesses, intervindo o Ministério Público em todos os atos do processo.

Atualmente está em tramitação no Congresso Nacional um projeto de criação do Estatuto dos Povos Indígenas para substituir o Estatuto do Índio. Enquanto, no entanto, não há a alteração da lei, deve ser aplicado o Estatuto do Índio à luz da Constituição, buscando diminuir a distância entre os avanços normativos e as práticas sociais e eliminando qualquer prevalência de interesses alheios à causa indígena.

\section{Considerações Finais}

A Constituição de 1998, portanto, tem como característica a proteção dos povos indígenas enquanto povos indígenas, com as características que lhes são peculiares, garantindo-lhes, a partir da instituição do novo paradigma da interação, no lugar da integração, o direito de ser e de permanecer índio, diferentemente do paradigma anterior que previa a integração do índio à civilização.

Devemo-nos atentar, contudo, que o Estatuto do Índio foi erigido sob a égide da ditatura militar, o qual, em que pese a sua recepção admitida pela nova ordem constitucional instaurada em 1988, ainda contém fundamentos autoritários que devem ser prontamente afastados quando de sua aplicação, que deve obedecer aos parâmetros estabelecidos pela ordem constitucional de 1988.

Assim, a interpretação de todo o Estatuto do índio deve ter por base o paradigma da interação, garantindo o direito de ser e de permanecer índio, consagrando o chamado direito à alteridade, instituído pela nova ordem constitucional. 


\section{Referências}

COLAÇO, Thais Luzia. Os "novos" direitos indígenas. In: WOLKMER, Antonio Carlos; LEITE, José Rubens Morato (orgs.). Os "novos" direitos no Brasil: naturezas e perspectivas: uma visão básica das novas conflituosidades jurídicas. São Paulo: Saraiva, 2003.

DALLARI, Dalmo de Abreu.Argumento antropológico e linguagem jurídica. In: SILVA, Orlando Sampaio; Luiz, Lídia; HELM, Cecília M.V. (Orgs.). A perícia antropológica em processos judiciais. Florianópolis: UFSC, 1994.

MAZUR, Bianca de Freitas. Os povos indígenas e seus direitos: a consagração com a Constituição de 1988. In: MINHOTO, Antonio (org.). Constituição, minorias e inclusão social. São Paulo: Rideel, 2009.

MENCK, José Theodoro Mascarenhas $\mathrm{O}$ problema indígena perante o ordenamento jurídico das Américas. In: Revista da OAB, ano XXII, v. XX, n.55, 1991.

OLIVEIRA, Paulo Henrique de, Direito Indígena à saúde: Proteção Constitucional e Internacional . Dissertação (Mestrado em Direito do Estado) - Pontifícia Universidade Católica de São Paulo. São Paulo, 2009.

SANTOS, Roberto Lemos Filho, Índios, convenção 169 da OIT e meio ambiente. In: Revista do CEJ. Brasília, n.22, jul./set. 2003.

http://www.cnv.gov.br/ Texto 5.

http://memoriasdaditadura.org.br/indigenas/ acesso em: 02/03/2017

http://memoriasdaditadura.org.br/indigenas/ acesso em: 25/10/2016

http://memoriasdaditadura.org.br/indigenas/ acesso em: 25/10/2016

Arquivo CNV, 00092.003063/2014-40, Depoimento de Oredes Krenak.

http://www.funai.gov.br/index.php/nossas-acoes/politica-indigenista?start=2 acesso em: $02 / 03 / 2017$

\section{Direito Indígena e o Paradigma Instituído pela Constituição de 1988: direito à alteridade}

\section{Resumo}

O presente trabalho tem como objeto de estudo o novo paradigma instituído pela Constituição Federal com relação aos direitos indígenas: a interação. Nesse sentido, a nova ordem constitucional garante o direito de ser e de permanecer índio, diversamente do paradigma anterior que previa a integração do índio à "civilização". Destarte, a partir do estudo do contexto de produção do Estatuto do Índio e da emergência da ordem constitucional de 1988, este estudo, realizado por método avaliativo-documental, busca compreender o contexto de produção do Estatuto do índio, atual legislação a eles aplicada, avaliando a necessidade de interpretação de tal lei à luz dos dispositivos constitucionais garantistas dos direitos dos índios.

Palavras-chave: Índio. Interação. Constituição de 1988.

Indigenous Rights and the Paradigm Established by the 1988 Constitution: right to otherness Abstract 
The present work has as object of study the new paradigm instituted by the Federal Constitution with respect to the indigenous rights: the interaction. In this sense, the new constitutional order guarantees the right to be and remain an Indian, unlike the previous paradigm that foresaw the integration of the Indian into "civilization". Thus, based on the study of the production context of the Indian Statute and the emergence of the constitutional order of 1988, this study, carried out by an evaluative-documentary method, seeks to understand the context of production of the Indian Statute, Assessing the need for interpretation of such law in the light of constitutional provisions that guarantee the rights of Indians.

Key-words: Indian. Interaction. Constitution of 1988

\section{Derecho Indígena y el Paradigma Instituido por la Constitución de 1988: derecho a la alteridade}

\section{Resumen}

El presente trabajo tiene como objeto de estudio el nuevo paradigma instituido por la Constitución Federal con relación a los derechos indígenas: la interacción. En ese sentido, el nuevo orden constitucional garantiza el derecho de ser y de permanecer indio, a diferencia del paradigma anterior que preveía la integración del indio a la "civilización". De este modo, a partir del estudio del contexto de producción del Estatuto del Indio y de la emergencia del orden constitucional de 1988, este estudio, realizado por método evaluativo-documental, busca comprender el contexto de producción del Estatuto del indio, actual legislación a ellos aplicada, evaluando la necesidad de interpretación de tal ley a la luz de los dispositivos constitucionales garantizados de los derechos de los indios.

Palabras clave: Indio. Interacción. Constitución de 1988. 